\title{
ORIGINAL \\ FACTORS ASSOCIATED WITH BREECH DELIVERY AT TERM
}

\author{
DR. ASLAM MAHMOOD MALIK, FCPS \\ Assistant Professor of Obs \& Gynae \\ Quaid-e-Azam Medical College \\ Bahawalpur
}
DR ABIDA RIAZ, MBBS
Obs \& Gynae Unit I
Bahawal Victoria Hospital
Bahawalpur

\author{
DR ASIA AZIZ, MBBS \\ Department of Community Medicine \\ Quaid-e-Azam Medical College \\ Bahawalpur
}
Dr. Capt (R) ljaz Ahmad Shah, M.Phil
Professor of Community Medicine
Quaid-e-Azam Medical College
Bahawalpur

\begin{abstract}
Objectives: To assess the various factors associated with breech delivery at term. Design: Case control study. Period: Apr 2004 to Sep 2004 Setting: Department of Obstetrics \& Gynaecology unit-I, Bahawal Victoria Hospital Bahawalpur. Materials \& Methods: This case control study was carried out in women with the age group 2040 years. Various risk factors (Parity, multiple pregnancy, placenta Previa, amount of liquor and congenital abnormalities) associated with breech (50 cases) at term (37-42 completed weeks) were compared with vertex (50 controls) after matching. Results: Different factors associated with breech were oligohydramnios $44 \%$ vs control group, placenta previa $34 \%$ vs control group, primiparity $46 \%$ vs control group, multiple pregnancy $14 \%$ vs control group and congenital abnormalities $18 \%$ vs control group. Conclusion: Our study concluded that factors associated with breech delivery were oligohydramnios, placenta previa, multiparty, multiple pregnancy \& congenital abnormalities.
\end{abstract}

\section{INTRODUCTION}

The breech presentation occurs when fetal buttocks or lower extremities present into the maternal pelvis. The incidence of breech deliveries is variable between different centers ${ }^{1}$.It complicates $3-4 \%$ of deliveries. The incidence of breech presentation is approximately $25 \%$ before 28 weeks of gestation, $14 \%$ at $29-32$ weeks and 2.2-3.7\% at term, $5 \%$ at 40 weeks $^{2}$. The occurrence of breech presentation decreases with advancing gestational age $\mathrm{ag}^{3,4,5,6}$. So the breech presentation is prevalent among pre-term deliveries ${ }^{7}$. The predisposing factors -for breech presentation are $^{8}$ fetal abnormalities, placenta previa, cornual placenta, short length of umbilical $\operatorname{cord}^{9}$, malformations of uterus, multiple pregnancies, multiparty, elderly primigravidity ${ }^{10}$, use of anti convulsant drugs. This study was carried out to know the common risk factors responsible for breech presentation.

\section{MATERIALS \& METHODS}

This case control study was conducted at the department of obstetrics \& Gynaecology unit-I Bahawal Victoria Hospital, Bahawalpur. 50 cases presenting with breech at term (37-42 weeks) and 50 controls (vertex) were included in the study after matching. 
Ultrasonography was performed in both cases and controls to know the position of placenta and amount of liquor. Diagnostic criteria for both cases and controls for all suspected factors except parity were based on ultrasonography while parity was recorded through questionnaire after verbal consent. Chi square test was applied as the test of significance.

\section{RESULTS}

Table I shows the relationship of parity (number of pregnancies) and the lie of fetus (cases \& controls). 23 out of 50 vs 12 out of 50 controls were primigravidas. The difference noted was statistically significant. Nulliparity is one of the risk factors which is associated with breech presentation.

Among the 50 breech subjects normal liquor was found in $15(30 \%)$ patients, abnormal liquori.e. oligohydramnios in $22(44 \%)$ patients and polyhydramnios in $13(26 \%)$ patients (Table .II). So oligohydramnios was found in $44 \%$ of cases. It is one of the important risk factors which is associated with breech presentation.

\begin{tabular}{|l|c|c|}
\hline \multicolumn{3}{|c|}{ Table I Breech and Parity } \\
\hline No of pregnancies & Cephalic & Breech \\
\hline Ist & 12 & 23 \\
\hline Subsequent (2-10) & 38 & 27 \\
\hline Total & 50 & 50 \\
\hline Chi Square $=5.3, \quad P$ Value $=<0.05 \quad$ Odds ratio $=1: 1.2$ \\
\hline
\end{tabular}

\begin{tabular}{|c|c|c|}
\hline \multicolumn{3}{|c|}{ Table II Breech and Liquor } \\
\hline Amount of Liquor & Cephalic & Breech \\
\hline Normal & 32 & 15 \\
\hline Abnormal Liquor & 18 & 35 \\
\hline *. Oligohydramnios & 06 & 22 \\
\hline *. Polyhydramnios & 12 & 13 \\
\hline
\end{tabular}

There is association of number of fetuses either singleton or multiple with breech presentation. Table III shows that number of multiple fetuses with breech presentation were 7 as compared to 3 in cephalic group.

\begin{tabular}{|l|c|c|}
\hline \multicolumn{2}{|c|}{ Table III Breech and no. of fetuses(Multiple Pregnancy) } \\
\hline No. of Fetuses & Control (Vertex) & Cases (Breech) \\
\hline Single & 47 & 43 \\
\hline Multiple & 3 & 7 \\
\hline Total & 50 & 50 \\
\hline
\end{tabular}

Chi Square $=1.76, \mathrm{P}$ Value $=>0.05$, Odds ratio $=1: 2.55$

\begin{tabular}{|l|c|c|}
\hline \multicolumn{3}{|c|}{ Table IV Breech \& Malformations } \\
\hline Congenital malformation & Cephalic & Breech \\
\hline Yes & 6 & 9 \\
\hline No & 44 & 41 \\
\hline Total & 50 & 50 \\
\hline Chi Square $=0.70, P$ Value $=>0.5$, Odds ratio $=1: 1.6$ \\
\hline
\end{tabular}

\begin{tabular}{|l|c|c|}
\hline \multicolumn{3}{|c|}{ Table V Placenta Previa \& Breech } \\
\hline Placenta previa & Cephalic (Control) & Breech (Cases) \\
\hline Yes & 7 & 17 \\
\hline No & 43 & 33 \\
\hline Total & 50 & 50 \\
\hline Chi Square $=5.4, \quad P$ Value $=<0.5 \quad$ Odds ratio $=1: 3.16$ \\
\hline
\end{tabular}

Nine cases with breech presentation had fetal congenital malformations as compared to 6 cases with cephalic presentation (Table IV).

Seventeenth cases out of 50 in breech presentation had placenta previa while 7 cases out of 50 in cephalic group had placenta previa. The difference noted was statistically significant (Table V).

\section{DISCUSSION}

In our study various risk factors affecting breech presentation were studied as compared to controls. The risk factors associated with breech presentation i.e. placenta previa (34\%), oligohydramnios(44\%), multiple 
pregnancies with first breech presentation(14\%) were comparatively more as compared to vertex presentation.

The results of our study are consistent with those of Richard Fisher ${ }^{11}$ and Andrew Jenis ${ }^{12}$.They concluded that fetal malformations and multiple gestation increase the likelihood of breech presentation. Carpenter ${ }^{13}$ found lethal renal malformations with breech presentation (48\% vs $04 \%$ ). Andrew Jenis observed congenital abnormalities in 09\% of term gestations with breech presentation. Our study revealed this ratio as $18 \%$ vs $12 \%$. So there is significant association of congenital anomalies with persistent breech presentation ${ }^{14,15}$. Congenital anomalies like hydrocephalus makes it more difficult to make the final shift to cephalic presentation. Our results agree with that of conducted by Roberts ${ }^{16}$ in which primary parity was one of the important predictors of breech presentation at term. Multiple fetuses due to less space in the uterus may position themselves head to foot. Hydramnios may allow the free movement of fetuses, contrary to that oligohydramnios may impede the final shift of the fetuses to cephalic presentation.

\section{REFERENCES}

1. Acien, $-P$. Breech presentation in Spain, 1992 : a collaborative study. Eur-J-Obstet-Gynecol-Reprod-Biol. 1995 Sep; 62(1) : 19-24

2. Penn JZ. Breech presentation. In: high risk pregnancy management option. 2nd ed. London: Har Coreot Publisher, 2003, 1025.50.

3. Writer WD. Breech presentation and multiple pregnancy: Obstetric aspect and anaesthtic management. Clins in Anaesth 1986; 4:305.20.

4. Seeds JW. Mal presentations in : Gabbe SG, Niebyl JR Simpson JL, editors, Obstetrics : Normal and Problem Pregnancies 2 nd edition New York. Churchill Livingstone: $1991 ; 539-72$.

5. Mokriski BK. Abnormal presentation and multiple gestation in: Chestnut DH, editor, Obstetric Anaesthesia: Principles and Practice, St.Louis : Mosby - year Book, $1994: 669-85$.
6. Richard Fisher. Breech Presentation in :William obstetrics. Gary Cuning Ham, editor 4ed. United States of America. MC Graw Hill Companies. 2001 : L 510 - 32

7. Kaplan B; Rabinerson D; Hirsch M; Mashiach R; Hod M; Neri A. Intrapartum management of the low birth weight breech fetus. Clin Exp Obstet Gynecol. 1995; 22(4):307-11

8. Hofmer. Abnormal fetal presentation and position in: Chamberlain, Philip sj(editors) Turnbulls obstetrics. $3^{\text {rd }} \mathrm{ed}$ London Har Court Publisher, 2001 : 545 - 49.

9. Wu JF; Chang S-Y; Hsu TY; Hsieh CH; Kung FT; Hwang F-R; Tsai Kaohsiung, Taiwan R.O.C..Multivariate analysis of the relationship between umbilical cord length and obstetric outcome. Changgeng-Yi-Xue-ZaZhi. 1996 sep; 19(3) : 247-52

10. Achanna S; Monga D. Performance of elderly primigravidae in Kelantan. Med-J-Malaysia. $1995 \mathrm{Mar}$ 50(1): $37-44$.

11. Richard Fischer, MD, Co-Division head, Maternal-Fetal medicine, Associate Professor, Department of Obstetrics and Gynaecology, Section of Maternal-Fetal Medicines,Cooper Hospital/University Medical center

12. Andrew Jenis, MD, Chairman Department of Emergency medicine, Cortland Memorial Hospital. Pregnancy, Breech Delivery. Last updated : August 11, 2003

13. Carpenter M-W; Corrado F; Sung J. Lethal fetal renal anomalies and obstetric outcome. Eur-J-ObstetGynecol-Reprod-Biol. 2000 Apr; 89(2): 149-52

14. Amoa A-B; Sapuri M; Klufio CA. Perinatal outcome and associated factors of persistent breech presentation at the Port Moresby General Hospital, Papua New Guinea. P-N-G-Med-J. 2001 Mar-Jun; 44(1-2) : 48-56

15. Tsai FJ; Tsai CH; Peng CT; Wu JY; Lien CH; Wang TR Different race, different face : minor anomalies in Chinese newborn infants. Acta-Paediatr. 1999 Mar; $88(3): 323-6$

16. Roberts CL; Algert CS; Peat B; Henderson-Smart D. Small fetal size: a risk factor for breech birth at term. Int-J-Gynaecol-Obstet. 1999 Oct; 67(1): 1-8. 